\title{
Anti-cracking Technology and Application of Fiber Reinforced Concrete on Bridge Deck Pavement
}

\author{
Li guo Pang ${ }^{1}$, Lei $\mathrm{Yu}^{2}$, Ming ming Chai ${ }^{*}$, Biao zhi Zhang ${ }^{3}$ \\ ${ }^{1}$ Guangdong Nanyue Transportation Investment and Construction Co. Ltd, Guangzhou, Guangdong, 510199, China \\ ${ }^{2}$ Beijing Xinqiao Technology Development Co.Ltd, Beijing, Beijing, 100088, China \\ ${ }^{3}$ Research Institute of Highway Ministory of Transport, Beijing, Beijing, 100088, China
}

\begin{abstract}
In order to make the bridge deck pavement not easy cracking, the anti-cracking technology is put into effect on a certain bridge. The cementing material is selected after analyzing the theory that how fiber can enhance the concrete anti-cracking performance. The proper fiber is selected by testing and comparing the dispersibility and hydroscopicity of three kinds of fibers. The proper content of fiber is found by test and comparing different fiber contents in the same mix proportion concrete. The fiber is sent into the in forcedmixing concrete plant by spreading the fiber on the crawler belt. The construction technology including slab treatment, transport, pave, vibrate and curing is put forward. After 1 year observing, there is no any cracking on the bridge deck pavement. The life of bridge is increased. The cost of maintain is decreased. The goal of anti-cracking has been achieved.
\end{abstract}

\section{Background}

The bridge deck pavement is the protective layer of the main structure of the bridge, which directly bears the rolling action of vehicles and is the first barrier to ensure the durability of the bridge. In addition, the bridge deck pavement is very easy to crack under bending because of it's the plate-shaped long strip structure [1].

Especially for the large span bridges of expressway, the requirements for the flexural performance of concrete are high. When the expressway is located in the western mountainous area, the anti-cracking performance requirements of the bridge deck pavement concrete is also relatively high because of the dry and windy weather.

\section{Project overview}

\subsection{Project introduction}

The total length of the certain highway project is $90 \mathrm{~km}$, the design load grade of bridge is highway-I, and the design flood frequency of bridge and culvert is $1 / 100$, and that of large (super large) bridge is $1 / 300$. There are 6 super large bridges, 72 major bridges, 5 interchanges and 2 separated overpasses, all of which are reinforced concrete structures.

\subsection{Engineering difficulties}

Due to the influence of dry and windy weather in the western mountainous area, the concrete bridge deck pavement is prone to shrinkage cracks because of the insufficient tensile strength before hardening after pouring[2]. There are many long-span bridges in the project, and the bridge deck pavement is plate-shaped structure. During the later operation period, under the upper wheel load effect, the cement concrete is easy to crack due to the vertical deflection, and it will reflect to the asphalt concrete surface, finally it will cause cracks on the pavement. The cracks not only affect the appearance, but also cause water carrying harmful substances into the pavement layer to corrode the bridge deck pavement structure, thus seriously affecting the service life of the whole bridge[3]. Therefore, the technical difficulty for the project is to solve the problem that the cement concrete is easy to crack and has poor flexural toughness.

\section{Principle of anti-cracking technology}

This project mainly uses the bridge function of fiber in cement concrete to reduce the shrinkage crack of cement concrete and increase the toughness of fiber reinforced concrete. The fiber in the concrete will be dispersed in the cement mortar. When the paving is subjected to bending, the bottom of the pavement will bear the tensile force. The concrete at both ends will be tightened when the fiber cracks at the bottom of the pavement. With the increase of the pressure on the upper part of the pavement, the cracks at the bottom of the pavement will expand, and the fiber will gradually pull out of the concrete instead of breaking suddenly, so as to play the role of crack resistance and toughening[4].There is an interface between the concrete substrate and the fiber, and the interfacial shear force is recorded as $\tau$. The fiber and concrete are initially in a bonding state, the end of fiber began to debond from the 
substrate under the action of $\mathrm{P}$ force and the fiber is gradually stretched and pulled out. With the continuous action of $\mathrm{P}$ force, the fiber completely debonds and the chemical bonding energy disappears. At this time, only the friction force acts. With the fiber pulling out, the shear surface becomes more and more small. The above is the micro pull-out mechanism of one fiber, and the macroscopic appearance of all fibers is that it gradually cracks and forms a fine crack instead of a through crack after the failure of fiber reinforced concrete, which is also the principle of improving the toughness of fiber enhanced concrete [5-6].

\section{Key points of anti-cracking design of fiber reinforced concrete for bridge deck pavement}

\subsection{Composition design of cementing materials}

From the theory of fiber crack resistance, it can be seen that the chemical bond energy and frictional shear force of cementing materials are directly related to the compactness of concrete. For example, the pull-out resistance of fiber mixed in the loose concrete is lower than that in the dense cement concrete[7].

However, what needs to be clarified here is that concrete is not the denser the better. The denser the concrete, the greater the chemical bond energy between fiber and concrete substrate. If the chemical bond energy is too large to exceed the tensile strength of the fiber, the fiber will also fracture at the same time when the concrete cracks, thus losing the process of gradually pulling out the crack resistance, and the effect of crack resistance and toughening also be lost. Therefore, the key point of the composition design of the fiber reinforced concrete cementing materials is the density of the substrate should be controlled to match the fiber properties, so that the fiber can play the maximum pull-out work when the concrete meets the strength requirements.

Two kinds of cementing materials are compared in this paper. One is cement, the other is cement mixed with $15 \%$ fly ash. The pull-out resistance of fiber is tested by adding the same amount of the same kind of fiber in the cement concrete. The test results show that the concrete fiber without fly ash has greater pull-out performance, so pure cement is selected as cementing material.

\subsection{Selection of fiber types}

\subsubsection{Fiber dispersion.}

Before the project determining the fiber type, the fiber dispersion test of PVA, PPTF and PP fiber is carried out. It is found that the dispersion of PPTF fiber and PVA fiber are well dispersed in concrete paste without agglomeration. Combining with the test results, the PPTF fiber and PVA fiber are selected as the spare fiber for the fiber reinforced concrete of bridge deck pavement.

\subsubsection{Water absorption of fibers.}

Form the performance test report of each fiber, the water absorption of the fibers can meet the engineering requirements of $1-2 \%$. However, the engineers found that some fibers mixed into the concrete will agglomerate, similar to cotton water absorption, which will absorb the free water in the concrete into the fiber system, resulting in the slump drop suddenly of the cement concrete. This kind of fiber mentioned above is not suitable to be used as anti-cracking fiber of concrete[8].In order to select the suitable fiber for cement concrete, the rapid water absorption test of PVA fiber and PPTF fiber is carried out. The specific measures are as follows, firstly weigh the same amount of PVA fiber and PPTF fiber respectively, and put them into the water, keep still for 1 minute, then remove them from the water with the grate, after 5 minutes weigh the fiber mass after absorbing water, and finally calculate the water absorption. The results show that the water absorption of the PVA fiber is higher than the PPTF fiber, so the PPTF fiber is selected as anti-cracking fiber in this project.

\subsubsection{Determination of fiber dosage.}

Some studies have shown that the fiber dosage is not the more the better. As a kind of impurity, too much fiber is harmful to the strength of cement concrete, and too little fiber can not play a good bridging role[9].In order to determine the suitable fiber dosage, the flexural strength, early anti-cracking and flexural toughness of fiber enhanced concrete with $0.3 \%, 0.6 \%$ and $0.9 \%$ PPTF fiber dosage are tested in this paper. It is found that the strength of cement concrete does not decrease when the fiber dosage is $0.6 \%$, and the anti-cracking and flexural toughness of the cement concrete are maximized. Therefore, $0.6 \%$ is determined as the best PPTF fiber dosage.

\section{Construction technology of fiber reinforced concrete on bridge deck pavement}

\subsection{Pretreatment of Bridge deck [10]}

During the prefabrication of the girder slab top surface, roughening is carried out to make the surface rough. The reinforcement mesh shall be bound firmly, and be welded with the embedded shear reinforcement of girder slab. In order to ensure the reinforcement protection layer thickness, the reinforcement mesh is supported and cushioned by planting reinforcement. Before pouring concrete, the dust on the bridge deck shall be blown away by high-pressure blower, and further cleaned with highpressure water gun to ensure that the girder slab top surface is clean and moist. 


\subsection{Planting reinforcement}

Through the comparison and analysis of interface rigid shear connectors and flexible shear connectors, the interface between girder slab and pavement is treated with the flexible shear connectors. The use of flexible shear connectors is more conducive to ensure the integrity of concrete. Through the calculation, analysis and experimental verification, it is shown that the most reasonable shear connector between concrete should be reinforced with $\Phi 8$ reinforcement.

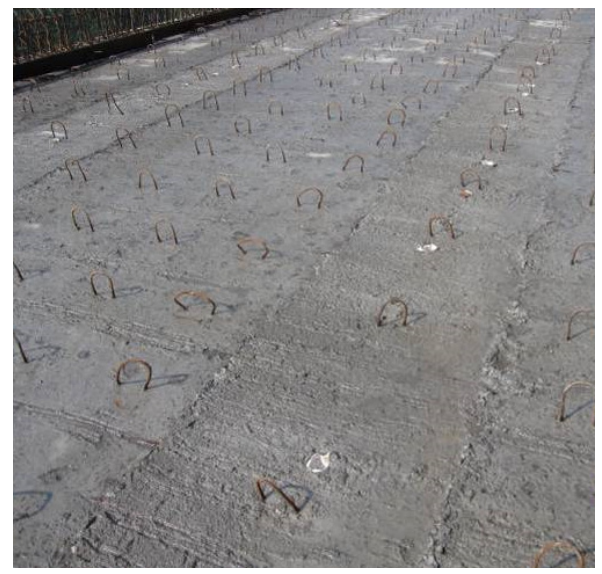

Figure 1. Flexible shear connector.

\subsection{Mixing process}

The preparation process of ultra-high toughness fiber reinforced concrete in the concrete mixing bin is roughly similar to that of ordinary concrete. The difference is that it is necessary to evenly distribute the fiber with the specified dosage on the conveyer belt after adding coarse aggregate when preparing fiber concrete. Figure 2 shows the feeding situation of technicians at the construction site.

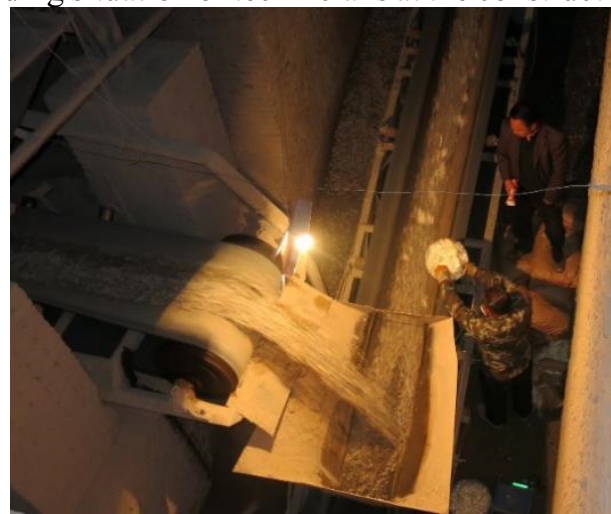

Figure 2. Put the fiber on the conveyer belt.

\subsection{Transportation}

The fiber reinforced concrete is transported by the mixer truck. During transportation, the stirring speed is $2 \mathrm{r} / \mathrm{min}$ $4 \mathrm{r} / \mathrm{min}$. When the mixer truck arrives at the pouring site, it rotates at the high speed for $20 \mathrm{~s}-30 \mathrm{~s}$, and then the fiber reinforced concrete mixture is fed into the concrete hopper. It should be noted that the time interval between the fiber concrete out of the machine and the start of pouring should not be greater than 60 minutes.

\subsection{Paving}

The fiber reinforced concrete is distributed manually. The concrete is poured on the designated position and roughly flattened by the shovel. It should be ensured that the paving height is $2 \mathrm{~cm}-3 \mathrm{~cm}$ higher than the design elevation. During the paving, in order to prevent the segregation of concrete, throwing and raking are strictly prohibited. If the fiber reinforced concrete is found to be agglomerated in the paving, it must be torn and shaken or removed in time manually. It should be noted that the time interval of the concrete between unloading and pouring shall not exceed 4 minutes.

\subsection{Vibration}

$10 \mathrm{~cm} \times 10 \mathrm{~cm}$ channel steel is used for the track of vibration beam, which is laid on the embedded supporting bar along the longitudinal direction of the bridge. The track supporting bars which is made of $\Phi 16$ reinforcement are embedded along the base of crash barrier to $0.5 \mathrm{~m}$ inside. In order to ensure that the track of the vibrating beam has sufficient stiffness and stability, the supporting bar is arranged every $0.5 \mathrm{~m}$. The supporting bar is composed of two vertical $\Phi 16$ reinforcements and one transverse $\Phi 16$ reinforcement, which the reinforcement are embedded in the bridge deck. After the vertical reinforcement of the supporting bar is embedded, the transverse reinforcement shall be welded in strict conformity with the elevation data provided by the surveyors. The channel steel track with $10 \mathrm{~cm} * 10 \mathrm{~cm}$ is laid on the welded transverse reinforcement, and the top elevation is the control elevation of the bridge deck pavement concrete. The track setting of vibrating beam and fully automatic truss type three roll shaft paver must be set strictly according to the setting out elevation.

\subsection{Leveling and plastering}

The concrete is scraped by manually with square steel, square wood or aluminum alloy ruler for 1-2 times to ensure the smoothness of the concrete surface. When there is no bleeding on the concrete surface, the disc type trowel shall be used to polish, finish and lift the slurry.The surface after troweling shall not expose fiber or leave laitance. The corner or small area can be plastered with the trowel.

\subsection{Joint cutting}

There is no longitudinal construction joint, a transverse false joint is set at the top of each pier, and for others, transverse false joints shall be set at a spacing of $15 \mathrm{~m}-20 \mathrm{~m}$ and aligned with the false joints of the crash barrier. The joint width is $3 \mathrm{~mm}-5 \mathrm{~mm}$, and the joint depth is $2.5 \mathrm{~cm}$. The joint cutting time is determined according to the air temperature and the concrete strength. Generally, the joint cutting is carried out when the concrete strength is $8 \mathrm{mpa}-$ $15 \mathrm{mpa}$, and the joint is filled with polyurethane tar after the cutting finished. 


\subsection{Curing}

After the concrete initial solidification, spray atomizing and moisture conservation is adopted. After the concrete surface is finished, the geotextile is lied and the water is sprayed for curing. In order to ensure the concrete strength and avoid the cracks, the curing time is not less than 7 days.

\section{Analysis of technical achievements and economic benefits}

The technical achievements are applied in the left side of the bridge deck pavement which is $120 \mathrm{~m}$ long and $12.2 \mathrm{~m}$ wide. The application of this achievement has achieved good results and considerable economic benefits, which are shown in the following three aspects:

- The service life of bridge deck pavement is increased. The average cost of bridge deck pavement is $¥ 300$ per square meter on average. The average service life of ordinary bridge deck pavement is calculated as 20 years, and the service life of fiber reinforced concrete bridge deck pavement is extended by 3 years on average, which saves the new pavement cost about $¥ 65900$.

- The service life of the bridge is increased. The average cost of bridge construction is $¥ 80000$ per linear meter on average. The design service life of bridge is 100 years. After using the fiber reinforced concrete, the service life of bridge is extended by 10 years, which saves the new bridge cost about $¥ 960000$.

- The maintenance cost is reduced. Compared with the ordinary concrete, the damage of bridge deck is reduced by $25 \%$ and the daily maintenance cost is decreased from 300 yuan $/ \mathrm{m}^{2}$ to $230 y u a n / \mathrm{m}^{2}$, after using fiber reinforced concrete, which saves the maintenance cost about $¥ 102500$.

The test section of $120 \mathrm{~m}$ long and $12.2 \mathrm{~m}$ wide bridge deck pavement of fiber reinforced concrete is estimated that the economic benefit will be $¥ 1128400$. There are 6 super large bridges $(12274 \mathrm{~m})$ and 72 bridges $(23599 \mathrm{~m})$ in the project. If the new materials are applied to all the bridge deck pavement, it is estimated that the economic benefit of $¥ 337.3263$ million will be generated.

\section{Conclusions}

Considering the applicability of fiber to concrete, the fiber with good dispersion and less water absorption is selected by the tests of dispersion and water absorption. In order to maximize the flexural toughness of concrete, the best fiber dosage is selected by testing the compressive strength, flexural toughness and anti-cracking of the cement concrete with three different fiber dosages. Considering the bond force between fiber and concrete, the mix proportion of concrete is optimized according to the composition of cementing materials. The fiber reinforced concrete with good tensile strength, bending strength, anti-cracking and bending toughness is obtained, and it is successfully applied in the left side of the bridge deck pavement which is $120 \mathrm{~m}$ long and $12.2 \mathrm{~m}$ wide.
- A simple test method for testing fiber dispersion and water absorption is proposed, which is convenient for engineering to select the suitable fiber quickly.

- The design conditions of fiber reinforced concrete mix proportion matching the fiber material properties and concrete strength are put forward. The optimized fiber reinforced concrete is successfully applied in the project, and the good construction effect is achieved. It can provide the theoretical and engineering support for fiber reinforced concrete material mix proportion design.

- The construction technology of fiber reinforced concrete on bridge deck pavement is proposed. Although it is not included in the specification, it can provide technical reference for other fiber reinforced concrete bridge deck pavement construction.

\section{References}

1. Liu, Z.L., Xie, H.Y., Yu, L., Zhang, G.Q.(2016) Analysis of Flexural Toughness of Fiber Reinforced Concrete for Deck Pavement. Journal of Highway and Transportation Research and Development(Applied Technology), 8:12-14.

2. Yu, L., Liu, Z.L., Zhang, G.Q., Zhang, S.X., Chen, L.(2017) Mix proportion design for bridge deck fiber concrete on durability. Concrete, 11:188-190.

3. Lv, D.W. (2013) Research on Comprehensive Technology of Cement Concrete Pavement with Asphalt Overlay in Expressway. Chang'an University.

4. Gao, B.T., Liu, Z.L., Yu, L.(2016) Optimization Design and Engineering Application of PVA Fiber Concrete Bridge Deck Pavement. Journal of Highway and Transportation Research and Development(Applied Technology), 10:173-176.

5. Lin, Z., Kanda,T., Victor,C.L. (1999) On interface property characterization and performance of fiberreinforced cementitious composites. Concrete Science and Engineering, 173-174.

6. Yu, L., Fu, Y.Y., Zhang, J., Wang, J.H. (2016) Test and Simulation on Pull-Out Behavior of Steel Wire in Foam Concrete. Journal of Harbin Institute of Technology, 48(6):119-123.

7. Yu, L., Liu, Z.L.(2016) Mechanical Properties Optimization of Fiber Reinforced Foam Concrete. Matec Web of Conferences, 67-75.

8. Feng, C. (2014) Study on the Early Stage Plastic Shrinkage and Cracking Performance of Ultra High Performance Concrete. Hunan University.

9. Deng, Z.C. (2016) Flexural Toughness and Characterization Method of Hybrid Fibers Reinforced Ultra-High Performance Concrete. Acta Materiae Compositae Sinica, 33(6):12741279.

10. Ministry of Housing and Urban-Rural Development of the People's Republic of China(MOHURD). (2010) Technical Specification 
for Application of Fiber Reinforced Concrete.

China Architecture \& Building Press, Beijing. 